\title{
Burkholderia mimosarum sp. nov., isolated from root nodules of Mimosa spp. from Taiwan and South America
}

Wen-Ming Chen, ${ }^{1}$ Euan K. James, ${ }^{2}$ Tom Coenye, ${ }^{3}$ Jui-Hsing Chou, ${ }^{4}$ Edmundo Barrios, ${ }^{5}$ Sergio M. de Faria, ${ }^{6}$ Geoffrey N. Elliott, ${ }^{2}$ Shih-Yi Sheu, ${ }^{7}$ Janet I. Sprent ${ }^{2}$ and Peter Vandamme ${ }^{3}$

Correspondence Wen-Ming Chen p62365@ms28.hinet.net

\author{
1Department of Seafood Science, National Kaohsiung Marine University, No. 142, \\ Hai-Chuan Road, Nan-Tzu, Kaohsiung City 811, Taiwan \\ ${ }^{2}$ School of Life Sciences, University of Dundee, Dundee DD1 5EH, UK \\ ${ }^{3}$ Laboratorium voor Microbiologie, Universiteit Gent, K. L. Ledeganckstraat 35, B-9000 Gent, \\ Belgium \\ ${ }^{4}$ Department of Soil Environmental Science, College of Agriculture and Natural Resources, \\ National Chung Hsing University, Taichung, Taiwan \\ ${ }^{5}$ Tropical Soil Biology and Fertility Institute of Centro Internacional de Agricultura Tropical \\ (TSBF-CIAT), A.A. 6713, Cali, Colombia \\ ${ }^{6}$ EMBRAPA-Agrobiologia, km 47, Seropedica, 23851-970 Rio de Janeiro, Brazil \\ ${ }^{7}$ Department of Marine Biotechnology, National Kaohsiung Marine University, Kaohsiung, \\ Taiwan
}

Fourteen strains were isolated from nitrogen-fixing nodules on the roots of plants of the genus Mimosa growing in Taiwan, Brazil and Venezuela. On the basis of 16S rRNA gene sequence similarities, all of the strains were previously shown to be closely related to each other and to belong to the genus Burkholderia. A polyphasic approach, including DNA-DNA reassociation, whole-cell protein analysis, fatty acid methyl ester analysis and extensive biochemical characterization, was used to clarify the taxonomic position of these strains: all 14 strains were classified as representing a novel species, for which the name Burkholderia mimosarum sp. nov. is proposed. The type strain, PAS44 ${ }^{\top}$ (=LMG $23256^{\top}=$ BCRC $17516^{\top}$ ), was isolated from Mimosa pigra nodules in Taiwan.
It is now generally accepted that legumes are not nodulated exclusively by members of the Rhizobiaceae in the Alphaproteobacteria, but may also be nodulated by members of the Betaproteobacteria (so-called 'legume-nodulating $\beta$-proteobacteria' or ' $\beta$-rhizobia') (Moulin et al., 2001). These include Cupriavidus taiwanensis (Chen et al., 2001, 2003a, b; Vandamme \& Coenye, 2004) and various Burkholderia strains (Moulin et al., 2001; Vandamme et al., 2002), two of which were classified as the novel species Burkholderia tuberum and Burkholderia phymatum (Vandamme et al., 2002). Until recently, the best evidence for nodulation of legumes by $\beta$-rhizobia had come from

The GenBank/EMBL/DDBJ accession number for the $16 \mathrm{~S}$ rRNA gene sequence of strain PAS44 ${ }^{\top}$ is AY752958.

Tables showing the DNA-DNA binding values, $\mathrm{G}+\mathrm{C}$ contents and fatty acid compositions of strain PAS44 ${ }^{\top}$ and related taxa, together with an extended neighbour-joining phylogenetic tree, are available as supplementary material in IJSEM Online. work with strains of $C$. taiwanensis. This species has been isolated from nodules of Mimosa pudica, Mimosa diplotricha and Mimosa pigra (synonym Mimosa pellita) in Taiwan (Chen et al., 2001, 2003a, 2005b) and from M. pudica in northern and southern India (Verma et al., 2004), and the type strain, LMG $19424^{\mathrm{T}}$, has been shown to nodulate $M$. pudica and $M$. diplotricha effectively (Chen et al., 2003b). More recently, there has been a greater focus on $\beta$-rhizobia in the genus Burkholderia, as these are being isolated from Mimosa and related species with much greater frequency than is C. taiwanensis, particularly in South America and Central America (Barrett \& Parker, 2005, 2006; Chen et al., 2005a), but also in Taiwan from the invasive legume $M$. pigra (Chen et al., 2005b). However, with the exception of Burkholderia caribensis TJ182, B. phymatum STM815 ${ }^{\mathrm{T}}$ and $B$. tuberum STM678 ${ }^{\mathrm{T}}$ (Vandamme et al., 2002), the taxonomic positions of Burkholderia legume symbionts have not yet been described. The aim of the present study was to clarify the taxonomic affiliation of a group of strains - isolated 
Table 1. Sources of the strains analysed

\begin{tabular}{|llc|}
\hline Strain & Host plant & Geographical origin \\
\hline Reported by Chen et al. $(\mathbf{2 0 0 5 b})$ & & Taiwan \\
PAS44 ${ }^{\mathrm{T}}\left(=\mathrm{LMG} 23256^{\mathrm{T}}=\mathrm{BCRC} 17516^{\mathrm{T}}\right)$ & M. pigra & Taiwan \\
PTK1 $(=$ LMG 23330) & M. pigra & Taiwan \\
PTK31 & M. pigra & Taiwan \\
PTU38 & M. pigra & Taiwan \\
PTU17 & M. pigra & Taiwan \\
PTU10 & M. pigra & \\
Reported by Chen et al. $(\mathbf{2 0 0 5 a})$ & & Venezuela \\
MAP3-1 & M. pigra & Venezuela \\
MAP3-2 & M. pigra & Venezuela \\
MAP3-3 & M. pigra & Venezuela \\
MAP3-4 & M. pigra & Venezuela \\
MAP3-5 (=LMG 23331) & M. pigra & Venezuela \\
MAP3-6 & M. pigra & Brazil \\
Br3454 & M. scabrella & Brazil \\
Br3467 & M. pigra & \\
\hline
\end{tabular}

from Mimosa nodules in Taiwan and South America - that have previously been shown via $16 \mathrm{~S}$ rRNA gene sequence analyses to be very closely related (Chen et al., 2005a, b).

The strains used in these studies are listed in Table 1. All 14 strains were isolated from root nodules of $M$. pigra, except for Br3454, which was isolated from Mimosa scabrella (de Faria et al., 1988). Details of the geographical origins of the strains have been described previously (Chen et al., 2005a, b). All were grown on yeast extract-mannitol agar plates (Vincent, 1970) and incubated at $28^{\circ} \mathrm{C}$ unless otherwise indicated. The Burkholderia reference strains have been described previously (Vandamme et al., 2002).

The 16S rRNA gene sequences of nine of the strains have been reported by Chen et al. (2005a, b) (see Fig. 1). These sequences were compared with published $16 \mathrm{~S}$ rRNA gene

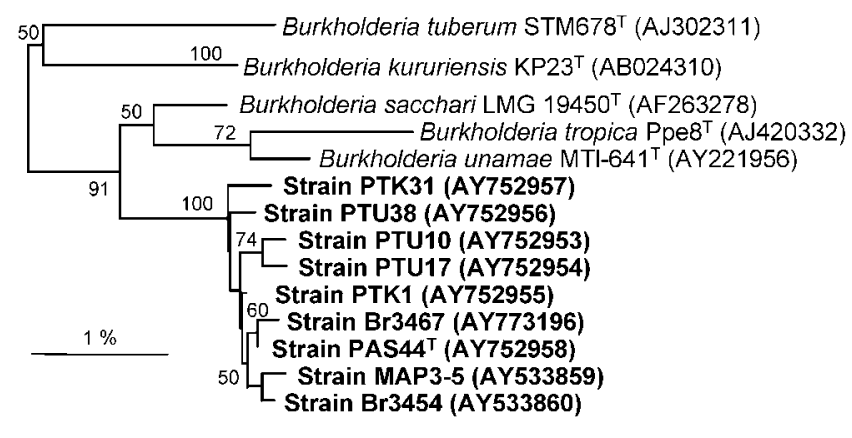

Fig. 1. Neighbour-joining phylogenetic tree of the novel strains (Burkholderia mimosarum sp. nov.) and related bacteria, based on $16 \mathrm{~S}$ rRNA gene sequence comparisons. Accession numbers are given in parentheses. Bar, $1 \%$ sequence dissimilarity. The full tree from which Fig. 1 was taken is available as Supplementary Fig. S1 in IJSEM Online. sequences of other Burkholderia species, as described previously (Chen et al., 2001, 2005a). The phylogenetic analysis showed that these nine strains form a single cluster $(99 \cdot 5-$ $100.0 \% 16 \mathrm{~S}$ rRNA gene sequence similarity) and belong to the genus Burkholderia within the Betaproteobacteria. Comparison of the 16S rRNA gene sequences of the nine strains with those of their closest neighbours, Burkholderia sacchari, Burkholderia unamae and Burkholderia tropica, revealed $97 \cdot 1-97 \cdot 9,96 \cdot 5-97 \cdot 5$ and $96 \cdot 0-96 \cdot 5 \%$ similarity, respectively (Fig. 1). Sequence similarities with respect to other Burkholderia species were below $96 \%$.

DNA samples were prepared from strains PAS44 ${ }^{\mathrm{T}}$, PTK1, MAP3-5, PTU17, PTK31, PTU38, PTU10, Br3467 and Br3454 as described by Pitcher et al. (1989). For determination of the DNA G $+C$ contents, DNA was degraded enzymically into nucleosides as described by Mesbah et al. (1989). The nucleoside mixture obtained was separated by HPLC using a Waters Symmetry Shield C8 column at $37^{\circ} \mathrm{C}$. The solvent was $0.02 \mathrm{M} \mathrm{NH}_{4} \mathrm{H}_{2} \mathrm{PO}_{4}(\mathrm{pH} 4 \cdot 0)$ with $1.5 \%$ acetonitrile. Non-methylated lambda phage DNA (Sigma) was used as the calibration reference. DNA-DNA hybridizations were performed with photobiotin-labelled probes as described by Ezaki et al. (1989). The hybridization temperature was $50{ }^{\circ} \mathrm{C}$ and the reaction was carried out in $30 \%$ formamide. Each value obtained was the mean of two hybridization experiments. The DNA G $+\mathrm{C}$ contents of the strains examined were in the range $63 \cdot 8-64 \cdot 8 \mathrm{~mol} \%$; the DNA-DNA binding values among these nine strains varied between 79 and $100 \%$ (see Supplementary Table S1 in IJSEM Online). The mean binding values with respect to the closest phylogenetic neighbours, B. unamae, B. tropica and $B$. sacchari, were found to be 32,46 and $53 \%$, respectively (Fig. 1), and values of $56 \%$ or less were calculated in relation to the type strains of other Burkholderia species (Supplementary Table S1). 
Differentiation of the novel strains from their closest phylogenetic neighbours was examined by using several approaches. For the analysis of protein electrophoretic patterns, strains were grown on nutrient agar (CM3; Oxoid) supplemented with $0.04 \%(\mathrm{w} / \mathrm{v}) \quad \mathrm{KH}_{2} \mathrm{PO}_{4}$ and $0.24 \%(\mathrm{w} / \mathrm{v})$ $\mathrm{Na}_{2} \mathrm{HPO}_{4} \cdot 12 \mathrm{H}_{2} \mathrm{O}(\mathrm{pH} 6 \cdot 8)$ and incubated for $48 \mathrm{~h}$ at $28^{\circ} \mathrm{C}$. The preparation of whole-cell proteins and the performance of SDS-PAGE were carried out as described by Pot et al. (1994). Densitometric analysis, normalization and interpolation of the protein profiles and numerical analysis using the Pearson product-moment correlation coefficient were performed using the GelCompar 4.2 software package (Applied Maths). Whole-cell protein extracts from the Mimosa isolates were prepared and compared with others present in our database. All of the novel strains formed a single cluster with similarities of more than $72 \%$; this compares with similarities of less than $68 \%$ with other Burkholderia species (Fig. 2). For fatty acid methyl ester analyses, $10 \mu \mathrm{l}$ cell culture was harvested after incubation at $28{ }^{\circ} \mathrm{C}$ for 24 h. Fatty acid methyl esters were then prepared, separated and identified using the Microbial Identification System (Microbial ID) as described previously (Vandamme et al., 2002). The fatty acid profiles of strains PAS44 ${ }^{\mathrm{T}}$, PTK1 and MAP3-5 were determined and then compared with those of other Burkholderia species (see Supplementary Table S2 available in IJSEM Online). The fatty acid profiles of these three Mimosa strains and other reference strains were similar and showed a predominance of the following fatty acids: $16: 0,18: 1 \omega 7 c$, summed feature 2 (comprising 14:0 3-OH, 16:1 iso I, an unidentified fatty acid with an equivalent chain-length value of 10.928 or $12: 0$ ALDE, or any combination of these fatty acids) and summed feature 3 (comprising $16: 1 \omega 7 c$ or 15 iso $2-\mathrm{OH}$ or both). The fatty acid profile of strain PAS44 ${ }^{\mathrm{T}}$ consisted of the following: $14: 0 \quad(3 \cdot 6 \pm 0 \cdot 1 \%), \quad 16: 0 \quad(19 \cdot 1 \pm 0 \cdot 4 \%), \quad 16: 0 \quad 2-\mathrm{OH}$
$(1 \cdot 6 \pm 0 \cdot 1 \%), 16: 03-\mathrm{OH}(4 \cdot 2 \pm 0 \cdot 1 \%), 16: 12-\mathrm{OH}(0 \cdot 9 \pm$ $0 \cdot 1 \%), 17: 0$ cyclo $(3 \cdot 3 \pm 0 \cdot 3 \%), 18: 1 \omega 7 c(45 \cdot 6 \pm 1 \cdot 0 \%)$, $18: 12-\mathrm{OH}(1 \cdot 0 \pm 0 \cdot 1 \%), 19: 0$ cyclo $\omega 8 c(1 \cdot 8 \pm 0 \cdot 2 \%)$ and summed features $2(5 \cdot 2 \pm 0 \cdot 1 \%)$ and $3(12 \cdot 6 \pm 0 \cdot 6 \%)$. Finally, amplified rDNA restriction analysis of all 14 Mimosa strains has been described previously by Chen et al. (2005b). The Burkholderia strains isolated from Taiwan contained two amplified rDNA restriction analysis types and formed a single cluster together with the Venezuelan strains (MAP31, MAP3-2, MAP3-3, MAP3-4, MAP3-5) and the Brazilian strains (Br3454 and Br3467) with at least $91 \%$ banding similarity. This compared with a figure of less than $85 \%$ for banding similarity with other nodulating Burkholderia strains (Chen et al., 2005b).

For biochemical characterization, the API 20NE and API ZYM microtest systems were used according to the recommendations of the manufacturer (bioMérieux). For carbonsubstrate assimilation tests, Biolog GN2 microtitre test plates were used. Early exponential phase cultures were used as inocula for the test plates $(150 \mu \mathrm{l}$ per well). Plates were incubated at $28^{\circ} \mathrm{C}$ and examined after 24 and $48 \mathrm{~h}$ to allow the development of a purple colour indicative of substrate oxidation. When the API 20NE microtest gallery was used, the following characteristics were present for all strains: oxidase activity, catalase activity and the assimilation of glucose, arabinose, mannitol, $\mathrm{N}$-acetylglucosamine and malate. The following characteristics were uniformly absent: indole production, glucose fermentation, arginine dihydrolase activity, aesculin hydrolysis, gelatin hydrolysis, $\beta$-galactosidase activity and the assimilation of maltose, caprate, adipate and citrate. The following characteristics were strain-dependent: nitrate reduction, urease activity and the assimilation of mannose, phenylacetate and gluconate.

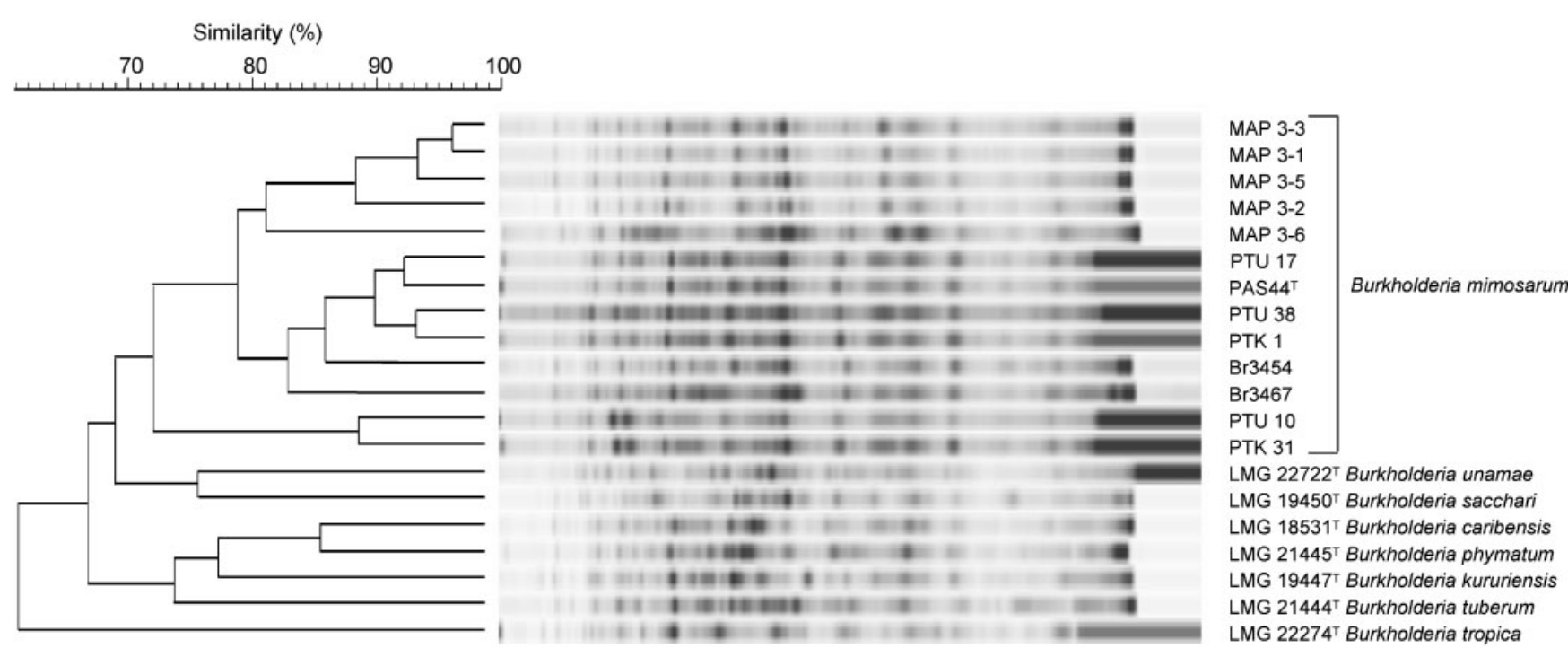

Fig. 2. Dendrogram showing whole-cell protein profiles and the result of a numerical comparison of the protein profiles of the Mimosa isolates and type strains of Burkholderia species. 
When the API ZYM microtest gallery was used, the following characteristics were present in all strains: alkaline phosphatase, C8 lipase, leucine arylamidase, acid phosphatase and naphthol-AS-BI-phosphohydrolase activities. The following characteristics were uniformly absent: C14 lipase, valine arylamidase, cystine arylamidase, trypsin, $\alpha$-chymotrypsin, $\alpha$-galactosidase, $\beta$-galactosidase, $\beta$-glucuronidase, $\alpha$-glucosidase, $\beta$-glucosidase, $N$-acetyl- $\beta$-glucosaminidase, $\alpha$-mannosidase and $\alpha$-fucosidase activities. C4 esterase activity was strain-dependent.

When the Biolog GN2 microtitre test system was used, the following substrates were oxidized: dextrin, glycogen, Tweens 40 and 80, $\mathrm{N}$-acetyl-D-glucosamine, arabinose, arabitol, i-erythritol, D-fructose, L-fucose, D-galactose, $\alpha$-Dglucose, myo-inositol, D-mannitol, D-mannose, D-sorbitol, methyl pyruvate, monomethyl succinate, acetic acid, cis-aconitic acid, citrate, formic acid, D-galacturonic acid, D-glucosaminic acid, $\alpha$ - and $\beta$-hydroxybutyric acids, $p$-hydroxyphenylacetic acid, $\alpha$-ketoglutaric acid, DL-lactate, propionic acid, quinic acid, D-saccharic acid, sebacic acid, succinic acid, bromosuccinic acid, D- and L-alanine, L-aspartic acid, L-glutamic acid, L-histidine, hydroxy-Lproline, L-leucine, L-phenylalanine, L-proline, L-pyroglutamic acid, L-serine, L-threonine and $\gamma$-aminobutyric acid. None of the strains oxidized $\alpha$-cyclodextrin, $N$-acetyl-D-galactosamine, adonitol, cellobiose, gentiobiose, $\alpha$-D-lactose, maltose, D-melibiose, methyl $\beta$-D-glucoside, D-raffinose, L-rhamnose, sucrose, D-trehalose, turanose, xylitol, D-glucuronic acid, $\gamma$-hydroxybutyric acid, itaconic acid, $\alpha$-ketovaleric acid, glucuronamide, inosine, uridine, thymidine, 2,3-butanediol, DL- $\alpha$-glycerol phosphate, glucose 1-phosphate or glucose 6-phosphate. Oxidation of the following substrates was strain-dependent: lactulose, D-psicose, D-galactonic acid lactone, D-gluconic acid, $\alpha$-ketobutyric acid, malonic acid, succinamic acid, alaninamide, L-alanyl glycine, L-asparagine, glycyl L-aspartic acid, glycyl L-glutamic acid, L-ornithine, D-serine, DL-carnitine, urocanic acid, phenylethylamine, putrescine, 2-aminoethanol and glycerol.

A comparison of the biochemical characteristics of strain PAS44 ${ }^{\mathrm{T}}$ with those of the type strains of 20 closely related Burkholderia species is shown in Table 2. Strain PAS44 ${ }^{\mathrm{T}}$ can be differentiated from $B$. sacchari by the oxidation of adonitol, raffinose and sucrose, and from $B$. unamae and $B$. tropica by the oxidation of adonitol, arabitol, cellobiose, rhamnose and trehalose. Strain PAS44 ${ }^{\mathrm{T}}$ is the only strain within the Burkholderia cluster tested in this work that is negative for the oxidation of adonitol, rhamnose, sucrose and trehalose.

In conclusion, the present study demonstrated that 14 isolates from root nodules of $M$. pigra and M. scabrella from Taiwan, Brazil and Venezuela represent a single species that is readily distinguished from its nearest phylogenetic neighbours by means of their whole-cell protein (Fig. 2) and amplified rDNA restriction analysis profiles (Chen et al., 2005b), the results of DNA-DNA reassociation experiments (Supplementary Table S1) and the biochemical characterization (Table 2). Therefore the 14 novel strains can be classified as representing a novel species, for which we propose the name Burkholderia mimosarum sp. nov., with strain PAS $44^{\mathrm{T}}$ as the type strain. Isolates PAS44 ${ }^{\mathrm{T}}$, PTK1,

Table 2. Comparison of the oxidation of carbon sources by strain PAS $44^{\top}$ and type strains of Burkholderia species

Species/strain: 1, B. sacchari; 2, B. kururiensis; 3, B. phenazinium; 4, B. glathei; 5, B. cepacia; 6, B. pyrrocinia; 7, B. vietnamiensis; 8, B. glumae; 9, B. plantarii; 10, B. gladioli; 11, B. caryophylli 12, B. andropogonis; 13, B. mallei; 14, B. pseudomallei; 15, B. graminis; 16, B. caribensis; 17, B. unamae; 18, B. tropica; 19, B. phymatum; 20, B. tuberum; 21, strain PAS44 ${ }^{\mathrm{T}}$. The data in columns 1-18 are from Brämer et al. (2001), Reis et al. (2004) and Caballero-Mellado et al. (2004).

\begin{tabular}{|llllllllllllllllllllllllll}
\hline Carbon source & $\mathbf{1}$ & $\mathbf{2}$ & $\mathbf{3}$ & $\mathbf{4}$ & $\mathbf{5}$ & $\mathbf{6}$ & $\mathbf{7}$ & $\mathbf{8}$ & $\mathbf{9}$ & $\mathbf{1 0}$ & $\mathbf{1 1}$ & $\mathbf{1 2}$ & $\mathbf{1 3}$ & $\mathbf{1 4}$ & $\mathbf{1 5}$ & $\mathbf{1 6}$ & $\mathbf{1 7}$ & $\mathbf{1 8}$ & $\mathbf{1 9}$ & $\mathbf{2 0}$ & $\mathbf{2 1}$ \\
\hline Adonitol & + & + & + & + & + & + & - & + & - & + & + & + & - & - & + & + & + & + & + & + & - \\
Arabinose & + & + & + & + & + & + & + & + & + & + & + & + & - & - & + & + & + & + & + & + & + \\
Arabitol & + & + & + & + & + & + & + & + & + & + & + & + & - & + & + & + & - & - & + & + & + \\
Cellobiose & - & - & - & - & + & + & + & - & - & - & - & - & - & - & + & - & + & + & - & - & - \\
Fructose & + & + & + & + & + & + & + & + & + & + & + & + & - & + & + & + & + & + & + & + & + \\
Fucose & + & + & + & + & + & + & + & + & + & + & + & - & - & + & + & + & + & + & + & + & + \\
Lactose & - & - & - & + & - & - & - & - & - & - & - & + & - & - & + & + & - & + & - & - & - \\
Maltose & - & + & - & - & - & - & - & - & - & - & - & - & - & - & - & + & - & - & - & - & - \\
Melibiose & - & - & - & - & - & - & - & + & - & - & - & - & - & - & - & - & - & - & + & - & - \\
Raffinose & + & - & - & - & - & - & + & + & - & - & + & - & - & - & + & - & - & - & - & - & - \\
Rhamnose & - & + & + & + & - & - & - & - & + & - & + & - & - & - & + & + & + & + & + & + & - \\
Sorbitol & + & + & + & + & + & + & + & + & + & + & + & + & - & + & + & + & + & + & + & + & + \\
Sucrose & + & - & + & - & + & + & + & - & - & - & + & - & + & + & + & - & - & - & + & - & - \\
Trehalose & - & - & - & - & + & + & + & + & + & + & + & - & + & - & + & + & + & + & - & - & - \\
Xylitol & - & + & + & + & + & + & - & - & - & - & + & - & - & - & + & + & - & - & + & + & - \\
\hline
\end{tabular}


PTU38, PTU17, PTU10, PTK31, MAP3-5 and Br3454 effectively nodulated Mimosa species, and the presence of nif and nod genes in the genomes of strains PAS44 ${ }^{\mathrm{T}}$, MAP3-5 and Br3454 has been demonstrated (Chen et al., 2005a, b). Moreover, green fluorescent protein-expressing transconjugant derivatives of PAS44 ${ }^{\mathrm{T}}$ and MAP3-5 produced $\mathrm{N}_{2}$-fixing nodules on their original host, $M$. pigra (Chen et al., 2005a, b). These results strongly confirm that these Burkholderia strains can form effective symbioses with legumes of Mimosa species.

\section{Description of Burkholderia mimosarum sp. nov.}

Burkholderia mimosarum [mi.mo.sa' rum. N.L. gen. pl. n. mimosarum of mimosas (of Mimosa spp.), from which all the strains, including the type strain, were isolated].

Cells are Gram-negative, non-spore-forming and rodshaped. After $24 \mathrm{~h}$ growth on yeast extract-mannitol agar at $28^{\circ} \mathrm{C}$, the mean cell size is about $0 \cdot 5-0 \cdot 7 \mu \mathrm{m}$ (width) $\times$ $0 \cdot 8-2 \cdot 0 \mu \mathrm{m}$ (length). Growth is observed at 28,30 and $37^{\circ} \mathrm{C}$. Catalase- and oxidase-positive. Assimilates glucose, arabinose, mannitol, $\mathrm{N}$-acetylglucosamine and malate. Indole is not produced, gelatin and aesculin are not hydrolysed and glucose is not fermented. Does not assimilate maltose, caprate, adipate or citrate. Additional characteristics are listed above. The DNA G $+\mathrm{C}$ content is about $63 \cdot 8-64 \cdot 8 \mathrm{~mol} \%$. Strains have been isolated from root nodules of Mimosa pigra and Mimosa scabrella.

The type strain, PAS44 $4^{\mathrm{T}}\left(=\mathrm{LMG} 23256^{\mathrm{T}}=\right.$ BCRC $\left.17516^{\mathrm{T}}\right)$, was isolated from $M$. pigra nodules at Anso in south-east Taiwan. The phenotypic characteristics of the type strain are the same as those described for the species. Its DNA G $+\mathrm{C}$ content is $64 \cdot 8 \mathrm{~mol} \%$.

\section{Acknowledgements}

W.-M. C. was supported by grants from the National Science Council, Taipei, Taiwan, Republic of China (NSC 94-2320-B-022-001 and 94-2313-B-022-001). E. K. J., G. N. E. and J. I. S. were supported by the Natural Environment Research Council (NERC). We thank J. Euzéby for his advice on the nomenclature of the novel species.

\section{References}

Barrett, C. F. \& Parker, M. A. (2005). Prevalence of Burkholderia sp. nodule symbionts on four mimosoid legumes from Barro Colorado Island, Panama. Syst Appl Microbiol 28, 57-65.

Barrett, C. F. \& Parker, M. A. (2006). Coexistence of Burkholderia, Cupriavidus, and Rhizobium sp. nodule bacteria on two Mimosa spp. in Costa Rica. Appl Environ Microbiol 72, 1198-1206.

Brämer, C. O., Vandamme, P., da Silva, L. F., Gomez, J. G. C. \& Steinbüchel, A. (2001). Burkholderia sacchari sp. nov., a polyhydroxyalkanoate-accumulating bacterium isolated from soil of a sugar-cane plantation in Brazil. Int $J$ Syst Evol Microbiol 51, 1709-1713.
Caballero-Mellado, J., Martinez-Aguilar, L., Paredes-Valdez, G. \& Estrada-de los Santos, P. (2004). Burkholderia unamae sp. nov., an $\mathrm{N}_{2}$-fixing rhizospheric and endophytic species. Int $J$ Syst Evol Microbiol 54, 1165-1172.

Chen, W. M., Laevens, S., Lee, T. M., Coenye, T., de Vos, P., Mergeay, M. \& Vandamme, P. (2001). Ralstonia taiwanensis sp. nov., isolated from root nodules of Mimosa species and sputum of a cystic fibrosis patient. Int J Syst Evol Microbiol 51, 1729-1735.

Chen, W. M., James, E. K., Prescott, A. R., Kierans, M. \& Sprent, J. I. (2003a). Nodulation of Mimosa spp. by the $\beta$-proteobacterium Ralstonia taiwanensis. Mol Plant Microbe Interact 16, 1051-1061.

Chen, W. M., Moulin, L., Bontemps, C., Vandamme, P., Béna, G. \& Boivin-Masson, C. (2003b). Legume symbiotic nitrogen fixation by $\beta$-Proteobacteria is widespread in nature. J Bacteriol 185, 7266-7272.

Chen, W. M., de Faria, S. M., Straliotto, R. \& 10 other authors (2005a). Proof that Burkholderia strains form effective symbioses with legumes: a study of novel Mimosa-nodulating strains from South America. Appl Environ Microbiol 71, 7461-7471.

Chen, W. M., James, E. K., Chou, J. H., Sheu, S. Y., Yang, S. Z. \& Sprent, J. I. (2005b). $\beta$-Rhizobia from Mimosa pigra, a newly discovered invasive plant in Taiwan. New Phytol 168, 661-675.

de Faria, S. M., Hay, G. T. \& Sprent, J. I. (1988). Entry of rhizobia into roots of Mimosa scabrella Bentham occurs between epidermal cells. J Gen Microbiol 134, 2291-2296.

Ezaki, T., Hashimoto, Y. \& Yabuuchi, E. (1989). Fluorometric DNA-DNA hybridization in microdilution wells as an alternative to membrane filter hybridization in which radioisotopes are used to determine genetic relatedness among bacterial strains. Int $J$ Syst Bacteriol 39, 224-229.

Mesbah, M., Premachandran, U. \& Whitman, W. B. (1989). Precise measurement of the $\mathrm{G}+\mathrm{C}$ content of deoxyribonucleic acid by highperformance liquid chromatography. Int J Syst Bacteriol 39, 159-167.

Moulin, L., Munive, A., Dreyfus, B. \& Boivin-Masson, C. (2001). Nodulation of legumes by members of the $\beta$-subclass of proteobacteria. Nature 411, 948-950.

Pitcher, D. G., Saunders, N. A. \& Owen, R. J. (1989). Rapid extraction of bacterial genomic DNA with guanidium thiocyanate. Lett Appl Microbiol 8, 109-114.

Pot, B., Vandamme, P. \& Kersters, K. (1994). Analysis of electrophoretic whole-organism protein fingerprints. In Modern Microbial Methods: Chemical Methods in Prokaryotic Systematics, pp. 493-521. Edited by M. Goodfellow \& A. G. O’Donnell. Chichester: Wiley.

Reis, V. M., Estrada-de los Santos, P., Tenorio-Salgado, S. \& 10 other authors (2004). Burkholderia tropica sp. nov., a novel nitrogen-fixing, plant-associated bacterium. Int J Syst Evol Microbiol 54, 2155-2162.

Vandamme, P. \& Coenye, T. (2004). Taxonomy of the genus Cupriavidus: a tale of lost and found. Int J Syst Evol Microbiol 54, 2285-2289.

Vandamme, P., Goris, J., Chen, W. M., de Vos, P. \& Willems, A. (2002). Burkholderia tuberum sp. nov. and Burkholderia phymatum sp. nov. nodulate the roots of tropical legumes. Syst Appl Microbiol 25, 507-512.

Verma, S. C., Chowdhury, S. P. \& Tripathi, A. K. (2004). Phylogeny based on $16 \mathrm{~S}$ rDNA and nifH sequences of Ralstonia taiwanensis strains isolated from nitrogen-fixing nodules of Mimosa pudica, in India. Can J Microbiol 50, 313-322.

Vincent, J. M. (1970). A Manual for the Practical Study of Root Nodule Bacteria. Oxford: Blackwell Scientific. 